\title{
Chlorophyll $a$ fluorescence in sweet potatoes under different copper concentrations
}

\author{
C.C. Cuchiara ${ }^{1, *}$, I.M.C. Silva ${ }^{1}$, D.S. Dalberto ${ }^{1}$, M.A. Bacarin ${ }^{1}$ and J.A Peters ${ }^{1}$ \\ ${ }^{1}$ Department of Botany, Institute of Biology, Federal University of Pelotas, UFPel, Capão do Leão, RS, \\ 96160-000, Brazil. *Corresponding author: cccuchiara@hotmail.com
}

\begin{abstract}
Photosynthesis is one of the main plant metabolic processes affected by copper deficiency and toxicity. The objective of this study was to evaluate the effects of different copper concentrations on transient chlorophyll $a$ fluorescence and modulated fluorescence in sweet potatoes. Sweet potatoes were placed in a hydroponic system and grown for six days with a complete nutrient solution. The plants were then transferred to solutions with different copper concentrations $(0.041,0.082,0.123$ and $0.164 \mathrm{mM})$ for nine days. The solutions were renewed every three days, and the plants were evaluated at the end of the experiment. Increased copper availability $(0.123$ and $0.164 \mathrm{mM})$ positively influenced the structure and functionality of photosystem I (PSI). The increase in $\mathrm{Cu}$ availability also reduced the apparent electron transport rate in the PSII [ETR(II)], and the plants treated with 0.082 and $0.123 \mathrm{mM} \mathrm{Cu}$ were able to dissipate the excess light energy in the PSII and protect its units (NPQ and qN). A joint analysis of the data shows that high copper concentrations in the nutrient solution lead to reduced photochemical activity of the PSII, increased dissipation of light energy from this same photosystem and increased PSI efficiency in sweet potatoes.
\end{abstract}

Keywords: Micronutrient, photosynthesis, copper sulphate, fluorescence transient, modulated fluorescence

\section{Introduction}

Heavy metals are considered environmental pollutants due to their toxicity, persistence and non-degradability in the soil, and copper is one of the main environmental contaminants (Violante et al., 2010; Cambrollé et al., 2013). This metal, in low concentrations, is an essential micronutrient for plant growth and development, and it plays a role in important biological reactions, mainly as an enzymatic cofactor present in electron carrier molecules in photosynthetic (plastocyanin) and respiratory (cytochrome oxidase) processes. However, this element is highly toxic to plants at excess concentrations (Mateos-Naranjo et al., 2008).

The first effect of copper toxicity in most species occurs in the roots, but high concentrations can cause copper to be translocated to the shoots and to interfere in various physiological processes (Cambrollé et al., 2013). The thresholds of leaf 
copper concentration causing toxicity are highly variable and range between 0.02 and $0.1 \mathrm{mg} \mathrm{g}^{-1}$ dry mass (Kabata-Pendias and Pendias, 2001). High levels of copper have been related to reductions in or damages to plant growth, mineral nutrient absorption, photosynthetic activity, membrane permeability, protein synthesis, enzymatic activity and chromatin structure (Cataldo et al., 2011; Cambrollé et al., 2011; 2012).

In contaminated soils, plants behave in different manners when faced with abiotic stress, and evaluating the physiological responses of plants subjected to toxicity by heavy metals can help unveil strategies employed in the removal, accumulation and tolerance of heavy metals (Kabata-Pendias and Pendias, 2001; Cambrollé et al., 2013).

Photosynthesis is one of the main plant metabolic processes affected by copper toxicity, and studies that evaluate these effects have shown that this metal causes decreased photosynthesis due to altered photochemical reactions in photosystem II (PSII) or the inactivation of active reaction centres, reduced quantic yield and decreased electron transport on the acceptor side and on oxygen evolution (PeralesVela et al., 2007; Xia and Tian, 2009; Cambrollé et al., 2012; Oukarroum et al., 2012). Chlorophyll a fluorescence-transient analysis is an efficient tool for studying physiological aspects of structure and activity, especially in the PSII (Strasser et al., 2004), and it has been widely used to evaluate damages to the photosynthetic system of plants by various types of stress (Maxwell and Johnson, 2000).

The analysis of modulated chlorophyll $a$ fluorescence is a technique that enables the collection of qualitative and quantitative information about the organisation and functioning of the photosynthetic apparatus of plants based on the saturation pulse method
(Rohácek and Barták, 1999). The principle employed by this method has been used in plant physiology studies that need to quantify the contributions of the photochemical processes and the dissipation of non-photochemical energy in the PSII (Rohácek and Barták, 1999). According to studies by Cambrollé et al. (2011, 2012, 2013), high copper concentrations decreased PSII yield and efficiency as a consequence of the photoinhibition induced by light stress in yellow hornpoppy (Glaucium flavum), sea purslane (Halimione portulacoides) and 'sapeira' (Limoniastrum monopetalum).

The sweet potato [Ipomea batatas (L.) Lam.] is economically important in developing nations because in addition to providing essential nutrients, it is easily cultivated, has high biomass, is resistant to drought and has a low production cost (Low et al., 2007). In addition to these characteristics, sweet potatoes have been used as a model plant in studies of plant nutrition and metabolism due to their ease of propagation and fast growth (Adamski et al., 2011; 2012).

The objective of this study was to evaluate the effect of different copper concentrations on the chlorophyll $a$ fluorescence transient and modulated fluorescence in sweet potatoes.

\section{Materials and Methods}

\subsection{Plant material and growth conditions}

The sweet potato plants used in the study were obtained from apical branches that were approximately eight centimetres long and had four leaves per branch from plants rooted for five days in distilled water in a greenhouse. After rooting, the plants were placed in a continuous-flow root floating hydroponic system and were cultured using the Hoagland and Arnon (1938) 
complete nutrient solution for six days. The plants were then cultured in a nutrient solution for nine days with different copper concentrations: $0.041 ; 0.082$; 0.123 and $0.164 \mathrm{mM}$ in the form of copper sulphate $\left(\mathrm{CuSO}_{4} \cdot 5 \mathrm{H}_{2} \mathrm{O}\right)$. The concentrations were determined after preliminary experiments that showed that cultivation in concentrations lower than those cited did not cause changes in growth parameters, and the control concentration was set at $0.041 \mathrm{mM}$ copper. Every three days, the solution was renewed, and the $\mathrm{pH}$ was adjusted to \pm 5.8 . After the plants were exposed to the treatments for nine days, the chlorophyll $a$ fluorescence transient and modulated fluorescence were evaluated.

\subsection{Chlorophyll fluorescence transient}

The chlorophyll $a$ fluorescence transient was measured in intact, fully expanded leaves in the second node from the apex (20-25 leaves/treatment) with a HandyPea portable fluorometer (Hansatech, King's Lynn, Norfolk, UK), with a gain of 0.5 . The leaves were first adapted to the dark for 30 minutes and then subjected to a saturating light pulse (approximately $3,000 \mu \mathrm{mol} \mathrm{m} \mathrm{m}^{-2} \mathrm{~s}^{-1}$ ). The fluorescence intensities were measured for one second. The JIP test parameters were calculated based on the fluorescence intensities of $50 \mu \mathrm{s}$ (minimum fluorescence $-\mathrm{F}_{0}$ ), $100 \mu \mathrm{s}, 300 \mu \mathrm{s}$, $2 \mathrm{~ms}\left(\mathrm{~F}_{\mathrm{J}}\right), 30 \mathrm{~ms}\left(\mathrm{~F}_{\mathrm{I}}\right)$ and $\mathrm{F}_{\mathrm{M}}$ (maximum fluorescence) (Strasser et al., 1995).

\subsection{Modulated fluorescence}

Modulated chlorophyll $a$ fluorescence was measured with a Dual-PAM-100 fluorometer (Heinz Walz, Effeltrich, Germany). For this purpose, unexpanded leaves were exposed for 2 minutes to an increasing photon flux density (PFD) (varying from 0 to 531 $\mu \mathrm{mol}$ photons $\mathrm{m}^{-2} \mathrm{~s}^{-1}$ ). The following intensities were determined after exposure to each PFD: $\mathrm{F}_{0}$, (initial fluorescence in the light-adapted state), $\mathrm{F}_{\mathrm{M}}$ (maximum fluorescence in the dark-adapted state), $\mathrm{F}_{\mathrm{M}}$ ' (maximum fluorescence in the light-adapted state obtained after applying a saturating light pulse) and $\mathrm{F}_{\mathrm{S}}$ (fluorescence intensity in equilibrium, or steady state). The following items were calculated from these parameters: effective photochemical quantum yield of the PSII $\left[\varphi_{\mathrm{PSII}}=\left(\mathrm{F}_{0}{ }^{\prime}-\mathrm{F}_{\mathrm{S}}\right) / \mathrm{F}\right.$ $\left.{ }_{\mathrm{M}}^{\prime}\right)$ ], photochemical extinction coefficient $[\mathrm{qP}=$ $\left.\left(\mathrm{F}_{\mathrm{M}}{ }^{\prime}-\mathrm{F}_{\mathrm{M}}\right) /\left(\mathrm{F}_{\mathrm{M}}{ }^{\prime}-\mathrm{F}_{0}{ }^{\prime}\right)\right]$ (Genty et al., 1989), nonphotochemical extinction coefficient $\left[\mathrm{qN}=\left(\mathrm{F}_{\mathrm{M}}\right.\right.$ - $\left.\left.\mathrm{F}_{\mathrm{M}}{ }^{\prime}\right) /\left(\mathrm{F}_{\mathrm{M}}-\mathrm{F}_{0}{ }^{\prime}\right)\right]$ (Genty et al., 1989) and nonphotochemical extinction $\left[\mathrm{NPQ}=\left(\mathrm{F}_{\mathrm{M}}-\mathrm{F}_{\mathrm{M}}{ }^{\prime}\right) / \mathrm{F}_{\mathrm{M}}{ }^{\prime}\right)$ ] (Demmig-Adams, 1990). The apparent electron transfer rate of the PSII [ETR(II)] was calculated as $0.5 \times$ PFD $\times \varphi_{\text {PSII }} \times 0.84$, where 0.5 is the proportion of energy that reaches the PSII, and PFD is the irradiance absorbed by the leaf, considering 0.84 or $84 \%$ light intensity (Baker, 2008).

\section{Results}

3.1. Chlorophyll a fluorescence transient: Normalisation and subtraction of transients

The transient fluorescence intensity in leaves grown under different copper concentrations was represented by typical polyphasic curves (Figure 1a-1b). The plants cultivated in higher copper concentrations (0.123 and $0.164 \mathrm{mM})$ had decreased fluorescence from the $\mathrm{F}_{\mathrm{J}}(2 \mathrm{~ms})$ to $\mathrm{F}_{\mathrm{M}}(1 \mathrm{~s})$ steps, particularly at a concentration of $0.164 \mathrm{mM}$. 

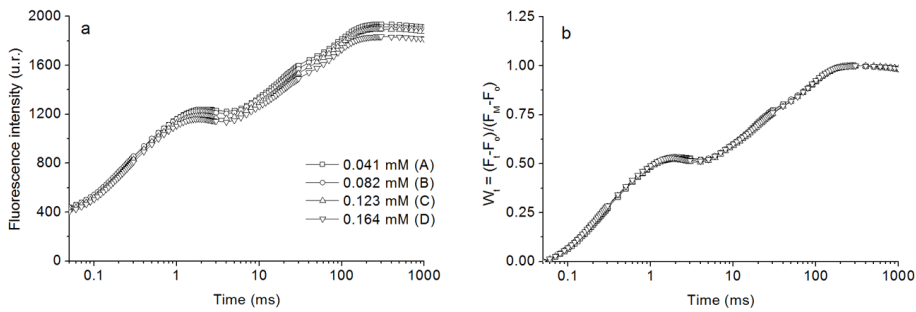

Figure 1. (a) Chlorophyll $a$ fluorescence transient in dark-adapted sweet potato (Ipomea batatas L.) leaves cultivated under different copper concentrations $\left(\mathrm{F}_{\mathrm{t}}\right)$; (b) Relative variable fluorescence $\left[\mathrm{W}_{\mathrm{t}}=\left(\mathrm{F}_{\mathrm{t}}-\mathrm{F}_{0}\right) /\left(\mathrm{F}_{\mathrm{M}}-\mathrm{F}_{0}\right)\right]$.

To allow the possible identification of L-bands (approximately $150 \mu \mathrm{s}$ ), the relative variable fluorescence was normalised between the points $0(50 \mu \mathrm{s})$ and $\mathrm{K}$ $(300 \mu \mathrm{s})\left(\mathrm{W}_{\mathrm{OK}}=\left[\mathrm{F}_{\mathrm{t}}-\mathrm{F}_{0}\right] /\left[\mathrm{F}_{\mathrm{K}}-\mathrm{F}_{0}\right]\right)$ (Figure 2a) and the kinetic difference was shown through the following equation: $\Delta \mathrm{W}_{\mathrm{OK}}=\left[\mathrm{W}_{\mathrm{OK}(\text { treatment) }}-\mathrm{W}_{\mathrm{OK} \text { (control) }}\right]$ (Figure $2 \mathrm{~b}$ ).
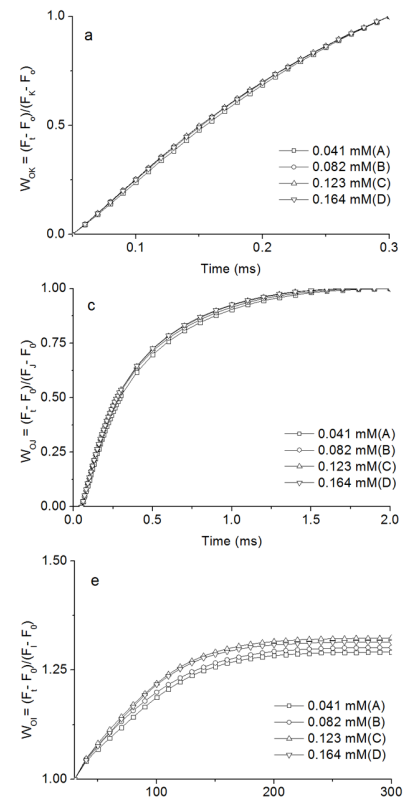

The appearance of the positive L-band indicates low energetic connectivity (or grouping) between the units of the PSII (Strasser and Stirbet, 1998; Yusuf et al., 2010). The present study identified the positive L-band in all the treatments, although with lower amplitude in the 0.164 $\mathrm{mM}$ concentration (Figure $2 \mathrm{~b}$ ).
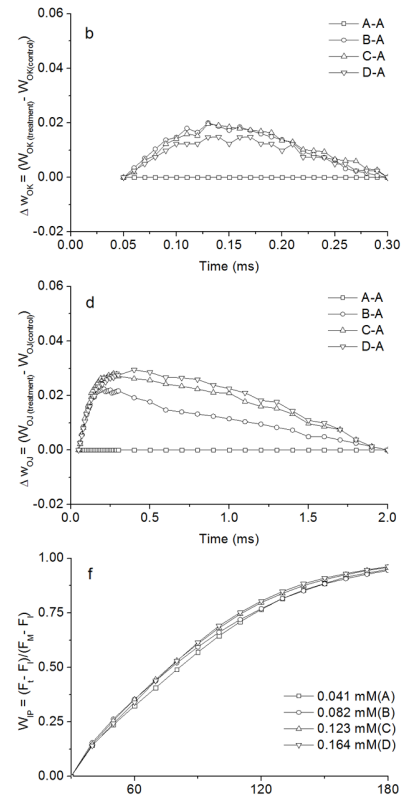

Figure 2. Chlorophyll $a$ fluorescence transient in dark-adapted sweet potato (Ipomea batatas L.) leaves cultivated with different copper concentrations: (a) Variable fluorescence between points $\mathrm{O}$ and $\mathrm{K}\left[\mathrm{W}_{\mathrm{OK}}=\left(\mathrm{F}_{\mathrm{t}}-\mathrm{F}_{0}\right) /\left(\mathrm{F}_{\mathrm{K}}-\mathrm{F}_{0}\right)\right]$; (b) Kinetic difference of $\mathrm{W}_{\mathrm{OK}}, \Delta \mathrm{W}_{\mathrm{OK}}=$ $\left[\mathrm{W}_{\mathrm{OK}(\text { treatrment }}-\mathrm{W}_{\mathrm{OK}(\text { control) }}\right] ;$ (c) Variable fluorescence between points $\mathrm{O}$ and J $\left[\mathrm{W}_{\mathrm{OJ}}=\left(\mathrm{F}_{\mathrm{t}}-\mathrm{F}_{0}\right) /\left(\mathrm{F}_{\mathrm{J}}-\mathrm{F}_{0}\right)\right]$; (d) Kinetic difference of $\mathrm{W}_{\mathrm{OJ}}, \Delta \mathrm{W}_{\mathrm{OJ}}$ $=\left[\mathrm{W}_{\mathrm{OJ} \text { (treatment) }}-\mathrm{W}_{\mathrm{OJ}(\text { control) }}\right]$; (e) Variable fluorescence between points $\mathrm{O}$ and $\mathrm{I}\left[\mathrm{W}_{\mathrm{OI}}=\left(\mathrm{F}_{\mathrm{t}}-\mathrm{F}_{0}\right) /\left(\mathrm{F}_{\mathrm{I}}-\mathrm{F}_{0}\right)\right]$ in the time interval of 30 to $330 \mathrm{~ms}$; (f) Variable fluorescence between points I and $\mathrm{P}\left[\mathrm{W}_{\mathrm{IP}}=\left(\mathrm{F}_{\mathrm{t}}-\mathrm{F}_{\mathrm{I}}\right) /\left(\mathrm{F}_{\mathrm{M}}-\mathrm{F}_{\mathrm{I}}\right)\right]$ in the time interval of 30 to $180 \mathrm{~ms}$. 
The K-band (approximately $300 \mu$ s) was observed when the variable fluorescence was normalised at the steps $0(50 \mu \mathrm{s})$ and $\mathrm{J}(2 \mathrm{~ms}), \mathrm{W}_{\mathrm{OJ}}=\left[\mathrm{F}_{\mathrm{t}}-\mathrm{F}_{0}\right] /$ $\left[\mathrm{F}_{\mathrm{J}}-\mathrm{F}_{0}\right]$ ) (Figure $2 \mathrm{c}$ ) and the kinetic difference was $\Delta \mathrm{W}_{\mathrm{OJ}}=\left[\mathrm{W}_{\mathrm{OJ}(\text { treatment) }}-\mathrm{W}_{\mathrm{OJ}(\text { control) }}\right]$ (Figure 2d). It was thus possible to identify the positive K-band in all of the concentration treatments studied. The positive $\mathrm{K}$-band indicates the inactivation of the oxygenevolving complex (OEC) and/or increased functional size of the antenna of the PSII (Yusuf et al., 2010).

To evaluate the effect of variation in copper concentration on the IP phase ( 30 to $300 \mathrm{~ms}$ ) of the fluorescence transient, the normalisations proposed by Yusuf et al. (2010), which are represented in Figure 2e-2f, were used. The relative variable fluorescence curve between steps $0(50 \mu \mathrm{s})$ and I $(30 \mathrm{~ms})\left(\mathrm{W}_{\mathrm{OI}}=\left[\mathrm{F}_{\mathrm{t}}\right.\right.$ $\left.-\mathrm{F}_{0}\right] /\left[\mathrm{F}_{\mathrm{I}}-\mathrm{F}_{0}\right]$ ) when $\mathrm{W}_{\mathrm{OI}} \geq 1$ (on a linear scale of 30 to
$300 \mathrm{~ms}$ ) reflects the size of the final electron acceptor pool on the acceptor side of the PSI (Figure 2e) (Yusuf et al., 2010). The highest concentrations (0.123 and $0.164 \mathrm{mM}$ ) resulted in increased acceptor abundance compared to the other concentrations. However, in the fluorescence normalisation of the IP phase $\left(\mathrm{W}_{\mathrm{IP}}=\left[\mathrm{F}_{\mathrm{t}}\right.\right.$ $\left.\left.-\mathrm{F}_{\mathrm{I}}\right] /\left[\mathrm{F}_{\mathrm{M}}-\mathrm{F}_{\mathrm{I}}\right]\right)$, there were no differences in the overall abundance of final electron acceptors (Figure 2f).

\subsection{Chlorophyll fluorescence transient: Parameters derived from the JIP Test equations}

The structural and functional parameters estimated from the OJIP transients by the JIP test are represented in the form of a radar chart (Figure 3), where all of the values were normalised for those obtained from the plants cultivated with $0.041 \mathrm{mM}$ copper (control).

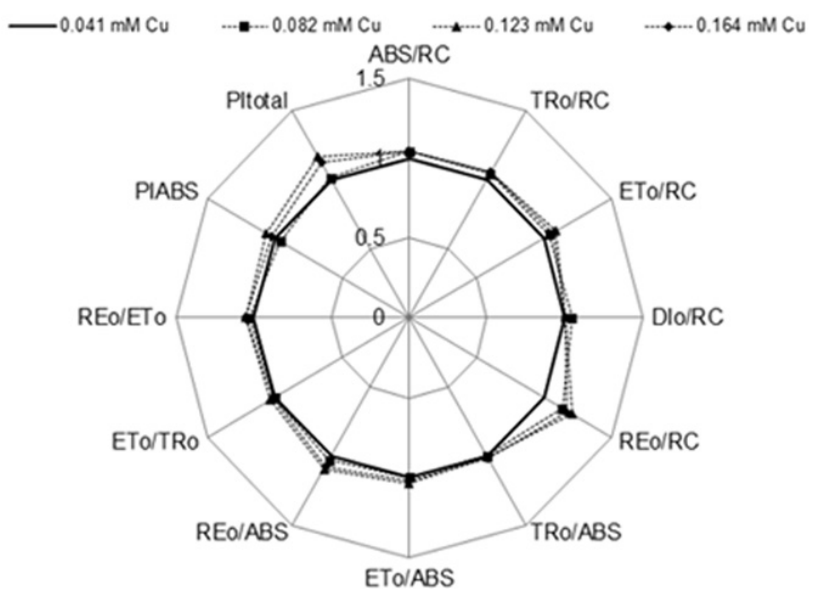

Figure 3. Chlorophyll $a$ fluorescence parameters obtained using the JIP test in sweet potatoes (Ipomea batatas L.) cultivated with different copper concentrations: $0.041 ; 0.082 ; 0.123$ and $0.164 \mathrm{mM}$.

The highest copper concentrations used $(0.082 ; 0.123$ and $0.164 \mathrm{mM}$ ) did not alter the energy flux absorbed (ABS/RC), captured $\left(\mathrm{TR}_{0} / \mathrm{RC}\right)$, transported $\left(\mathrm{ET}_{0} / \mathrm{RC}\right)$ and dissipated $\left(\mathrm{DI}_{0} / \mathrm{RC}\right)$ by the active reaction centres of the PSII compared to the control $(0.041 \mathrm{mM})$.
However, there was an increase of approximately $16 \%$ in the reduction flux of the final PSI electron acceptors $\left(\mathrm{RE}_{0} / \mathrm{RC}\right)$ per reaction centre in the plants cultivated in the higher copper concentrations $(0.082$; 0.123 and $0.164 \mathrm{mM})$. 
The treatments with different copper concentrations did not alter the parameters that expressed the maximum quantum $\operatorname{yield}\left(\varphi_{\mathrm{P}_{0}}=\mathrm{TR}_{0} / \mathrm{ABS}\right)$ and the quantum yield of the electron transfer from $\mathrm{Q}_{\mathrm{A}}{ }^{-}$to the intersystem electron acceptors $\left(\varphi_{\mathrm{Eo}}\right.$ $\left.=\mathrm{ET}_{0} / \mathrm{ABS}\right)$. However, there was a slight increase in the quantum yield of the reduction of the final PSI electron acceptor per absorbed photon $\left(\varphi_{\mathrm{Ro}}=\mathrm{RE}_{0} / \mathrm{ABS}\right)$ in the plants cultivated in high copper concentrations $(0.082 ; 0.123$ and $0.164 \mathrm{mM}$ ), which follows the results obtained in $\mathrm{RE}_{0} / \mathrm{RC}$. Increased copper concentration did not affect the parameters that describe the efficiency with which an exciton captured in the reaction centre can move an electron from $\mathrm{Q}_{\mathrm{A}}{ }^{-}$to the intersystem electron acceptor $\left(\psi_{\mathrm{Eo}}=\mathrm{ET}_{0} / \mathrm{TR}_{0}\right)$ and the efficiency with which an electron from the intersystem electron-carrier pool can reduce the final PSI electron acceptors or the probability of reduction of a final PSI electron acceptor $\left(\delta_{\mathrm{Ro}}=\mathrm{RE}_{0} / \mathrm{ET}_{0}\right)$.

The photosynthetic performance index relative to absorption $\left(\mathrm{PI}_{\mathrm{ABS}}\right.$ ) (proposed by Strasser et al., 2004) was not affected by the copper concentrations. However, the total photosynthetic performance index $\left(\mathrm{PI}_{\text {total }}\right)$, which measures the flux of electrons to the final PSI electron acceptors
(Tsimilli-Michael and Strasser, 2008), was altered by high copper concentrations. Regarding this parameter, the plants cultivated in a concentration of $0.082 \mathrm{mM}$ did not differ from the control, but the $\mathrm{PI}_{\text {total }}$ increased $15 \%$ in the plants that had a greater copper availability $(0.123$ and $0.164 \mathrm{mM})$.

\subsection{Modulated fluorescence}

The effective photochemical quantum yield of the PSII $\left(\varphi_{\mathrm{PSII}}\right)$ and the photochemical extinction coefficient (qP) (Figure 4a-4b) decreased from $22 \mu \mathrm{mol} \mathrm{m} \mathrm{m}^{-2} \mathrm{~s}^{-1}$ in all of the copper treatments, and in the plants treated with 0.164 $\mathrm{mM}$ of copper, the values of $\varphi_{\mathrm{PSI}}$, from this light intensity on were lower compared to the other concentrations. The parameters of the non-photochemical extinction (NPQ) (Figure 4c-4d) and the non-photochemical extinction coefficient were highly influenced by increased light intensity from $22 \mu \mathrm{mol} \mathrm{m} \mathrm{m}^{-2} \mathrm{~s}^{-1}$ on, and the plants cultivated in 0.082 and $0.123 \mathrm{mM}$ copper had higher NPQ and qN values than the control plants. In both of the cases, the plants cultivated in the copper concentration of $0.164 \mathrm{mM}$ had an intermediate response.
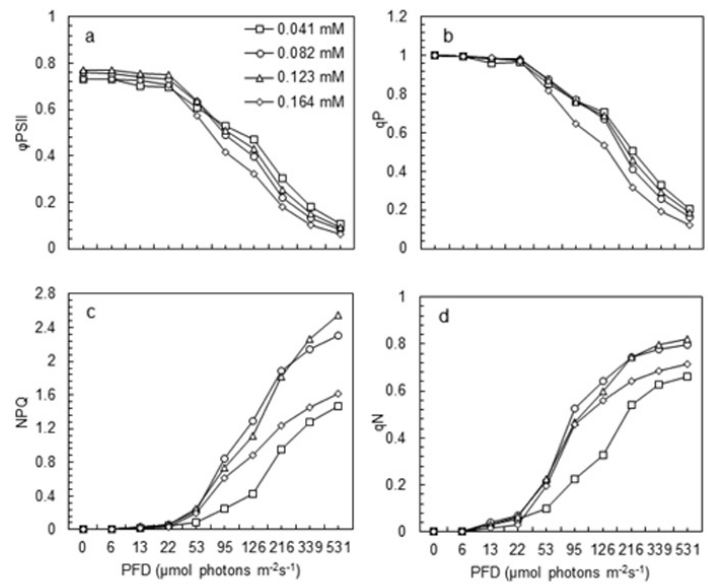

Figure 4. Light intensity response curves in sweet potatoes (Ipomea batatas L.) cultivated with different copper concentrations: (a) Effective photochemical quantum yield of the PSII ( $\left.\varphi_{\text {PSII }}\right)$; (b) Photochemical extinction coefficient of variable fluorescence of photosynthesis (qP); (c) Non-photochemical extinction (NPQ); (d) Non-photochemical extinction coefficient of variable fluorescence of photosynthesis $(\mathrm{qN})$. PFD = photosynthetically active photon flux density ( $\mu \mathrm{mol}$ photons $\left.\mathrm{m}^{-2} \mathrm{~s}^{-1}\right)$. 
The copper concentrations increased the apparent electron-transfer rate in the PSII [ETR(II)] up to $53 \mu \mathrm{mol} \mathrm{m}^{-2} \mathrm{~s}^{-1}$ light intensity. However, from this intensity on, there were different responses to the copper concentrations used (Figure 5). The control plants had the greatest ETR(II), followed by the intermediate doses ( 0.082 and $0.123 \mathrm{mM})$, and the lowest ETR(II) value was observed in the $0.164 \mathrm{mM}$ concentration.

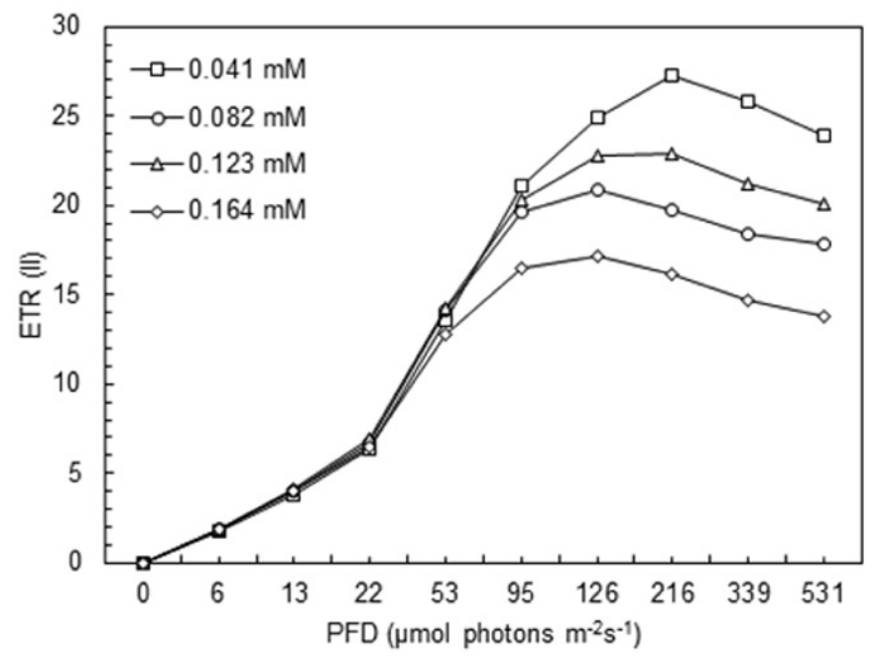

Figure 5. Variation of the electron transfer rate in the PSII, ETR (II) in sweet potatoes (Ipomea batatas L.) cultivated with different copper concentrations: $0.041 ; 0.082 ; 0.123$ and $0.164 \mathrm{mM}$. PFD = photosynthetically active photon flux density ( $\mu \mathrm{mol}$ photons $\left.\mathrm{m}^{-2} \mathrm{~s}^{-1}\right)$.

\section{Discussion}

Excess copper can cause toxic effects in plants, such as inhibited growth, damage to the photosynthetic apparatus and oxidative stress (Shi-Sheng, 2007; Cambrollé et al., 2013). Many researchers have conducted experiments on the effects of copper on physiological and biochemical processes of plants, and many studies have focused on the photosynthetic electron transport chain in plants (Cambrollé et al., 2011). However, few researchers have analysed detailed photosynthetic responses to increased copper levels using chlorophyll fluorescence analysis.

The fluorescence transient of the study plants had typical OJIP polyphasic curves for all of the copper treatments, which indicates that the photosynthetic units were active even under high copper concentrations. Fluorescence decreased from step J (2 $\mathrm{ms})$ to $\mathrm{F}_{\mathrm{M}}(1 \mathrm{~s})$ for the plants grown with the higher concentrations (0.123 and $0.163 \mathrm{mM}$ ) (Figure 1a). Decreased fluorescence at these levels is usually due to inhibition of electron transport on the donor side of the PSII, which is a result of the accumulation of P680+ (Perales-Vela et al., 2007; Oukarroum et al., 2012).

Analysis of the kinetic difference of the fluorescence transient curves (Figure 2b-2d) shows the appearance of the L-band and K-band. According to Strasser et al. (2004), the appearance of these positive bands indicates deleterious effects in plants. The positive L-bands in the sweet potato leaves cultivated under the three highest concentrations indicate that the 
PSII units were less grouped, which suggests a low connectivity between the PSII antenna units (Strasser et al., 2004). Decreased energetic connectivity is a partial protection mechanism in that it is necessary to increase dissipation to improve utilisation of the chlorophyll excitation energy in non-photochemical processes (Redillas et al., 2011). Furthermore, the ability to resist via decreased connectivity could be a measure of the ability to withstand alterations in the stacking or unstacking of the thylakoid membranes (Oukarroum et al., 2007).

A positive K-band indicates damages in the oxygenevolving complex (OEC) or increased functional size of the PSII antenna (Yusuf et al., 2010) (Figure 2d). In this study, the formation of K- and L-bands in plants cultivated in the presence of copper $(0.082$; 0.123 and $0.164 \mathrm{mM}$ ) is likely related to damages in the OEC of the PSII. This result can be explained by the accumulation of $\mathrm{P} 680^{+}$(Figure 1a). Similar results were found for magnesium deficiency in Citrus species (Yang et al., 2012) and excess iron in sweet potatoes (Adamski et al., 2011), but no Land K-bands appeared in Alternanthera tenella when using excess copper (Cuchiara et al., 2013).

Nevertheless, according to the results of chlorophyll $a$ fluorescence in a light-adapted state, the increased availability of copper did not decrease the PSII yield, as indicated by the results for $\varphi_{\mathrm{PSII}}$ and $\mathrm{qP}$ (Figure 4a$4 b)$. Leaves cultivated in high copper concentrations had a typical reduction in energy distribution in the PSII $\left(\varphi_{\text {PSII }}\right)$ and energy dissipation in photochemical processes $(\mathrm{qP})$ with increased light intensity (Figure $4 a-4 b)$, and the greatest reduction occurred at the $0.164 \mathrm{mM}$ copper concentration.

Decreases in the parameters $\varphi_{\mathrm{PSII}}$ and $\mathrm{qP}$ are reflected in the non-photochemical extinction (NPQ) and the non-photochemical extinction coefficient (qN) because both of these factors describe dissipation of excess energy in the form of heat in the PSII antenna complexes (Rohácek and Barták, 1999). Forms of absorbed energy dissipation include i) changes in the $\Delta \mathrm{pH}$ gradient, ii) disconnection of the mobile light-harvesting complexes, iii) transformation of violaxanthin into zeaxanthin and iv) protonation of the PsbS (integral membrane subunit of the PSII) (Rohácek and Barták, 1999; Baker, 2008). Greater values of NPQ and $\mathrm{qN}$ in the plants cultivated in 0.082 and $0.123 \mathrm{mM}$ copper suggests greater ability to dissipate energy in the form of heat as a strategy to protect photoinhibition of the PSII compared to the control plants. The plants cultivated under $0.164 \mathrm{mM}$ transferred more energy to other systems.

However, copper concentrations intensified PSI efficiency, as was observed in the chlorophyll $a$ fluorescence transience data. Analysis of the IP phase (Figure 2e-2f) revealed an increased final electronacceptor pool on the acceptor side of the PSI $\left(\mathrm{W}_{\mathrm{OI}}\right.$ $\geq 1)$ with increased copper availability ( 0.123 and $0.164 \mathrm{mM}$ ). Higher copper concentrations positively influenced the structure and functionality of the PSI due to increased reduction flux $\left(\mathrm{RE}_{0} / \mathrm{RC}\right)$ and yield $\left(\mathrm{RE}_{0} / \mathrm{ABS}\right)$ of the final PSI electron acceptors (Figure $3)$. Furthermore, the photosynthetic performance index also increased, related as $\mathrm{PI}_{\text {total }}=\mathrm{PI}_{\mathrm{ABS}} \cdot \delta_{\mathrm{Ro}_{\mathrm{o}}} /(1$ - $\delta_{\mathrm{Ro}}$ ), which incorporates the maximum performance for electron transfer from water to plastoquinone (PQ) and plastocyanin $(\mathrm{PC})$ by chlorophyll $\left(\mathrm{PI}_{\mathrm{ABS}}\right)$ and the performance of reduction of the final PSI acceptor (Strasser et al., 2010).

The joint analysis of the chlorophyll $a$ fluorescence in dark- and light-adapted states indicates that the copper concentrations had little effect on PSII structure and functionality because there were no marked alterations in the JIP test parameters. Under these conditions, there was only a reduction in the apparent electrontransfer rate in the PSII [ETR(II)] with increased light intensity (Figure 5). In addition, the plants treated with 0.082 and $0.123 \mathrm{mM}$ copper were able to dissipate 
the excess light energy in the PSII and protect its units through NPQ and qN (Munekage and Shikanai, 2005). NPN and $\mathrm{qN}$ activation depends on the generation of a proton gradient through the thylakoid membrane $(\Delta \mathrm{pH})$, which is induced by the linear and cyclic electron flow (Huang et al., 2012). Alternative electron transport pathways, cyclic electron transport in the PSI and the water-water cycle can regulate the induction of heat dissipation, which modifies the rate of $\Delta \mathrm{pH}$ generation (Munekage and Shikanai, 2005). However, PSI efficiency was intensified in the plants that grew in concentrations of 0.123 and $0.164 \mathrm{mM}$ copper. These results suggest that there may have been an increase in cyclic electron transport in the PSI. In this case, electrons returned from ferredoxin to plastoquinone, with ATP production and without NADPH accumulation (Munekage and Shikanai, 2005). Similar results were found in studies of water deficit (Huang et al., 2012), which suggests that plants cultivated in copper concentration of $0.123 \mathrm{mM}$ simulated drought-related situations and developed strategies to avoid photoinhibition of the photosynthetic apparatus caused by light energy absorption.

\section{Conclusions}

High copper concentrations in the nutrient solution alter transient and modulated chlorophyll $a$ fluorescence, reduce photochemical activity, increase the light energy dissipation of the PSII and increase PSI efficiency in sweet potato plants.

\section{Acknowledgements}

This study was funded by the Brazilian Federal Agency for the Support and Evaluation of Graduate Education (Coordenação de Aperfeiçoamento de
Pessoal de Nível Superior - CAPES), National Counsel for Scientific and Technological Development (Conselho Nacional de Desenvolvimento Científico e Tecnológico - CNPq) and the Funding Authority for Studies and Projects (Financiadora de Estudos e Projetos - FINEP/MCT).

\section{References}

Adamski, J.M., Peters, J.A., Danieloski, R., Bacarin, M.A. 2011. Excess iron-induced changes in the photosynthetic characteristics of sweet potato. J. Plant Physiol. 168, 2056-2062.

Adamski, J.M., Danieloski, R., Deuner, S., Braga, E.J.B., Castro, L.A.S., Peters, J.A. 2012. Responses to excess iron in sweet potato: impacts on growth, enzyme activities, mineral concentrations, and anatomy. Acta Physiol. Plant. 34 (5), 1827-1836.

Baker, N.R. 2008. Chlorophyll Fluorescence: A Probe of Photosynthesis In Vivo. Annu. Rev. Plant Biol. 59, 89-113.

Cambrollé, J., Mancilla-Leytón, J.M., Muñoz-Vallés, S., Figueroa-Luque, E., Luque T., Figueroa M.E. 2013. Effects of copper sulfate on growth and physiological responses of Limoniastrum monopetalum. Environ. Sci. Pollut. Res. 20, 8839-8847.

Cambrollé, J., Mateos-Naranjo, E., Redondo-Gómez, S., Luque, T., Figueroa M.E. 2011. Growth, reproductive and photosynthetic responses to copper in the yellow-horned poppy, Glaucium flavum Crantz. Environ. Exp. Bot. 71, 57-64.

Cambrollé, J., Mancilla-Leytón, J.M., Muñoz-Vallés, S., Luque, T., Figueroa, M.E. 2012. Tolerance and accumulation of copper in the salt-marsh shrub Halimioneportulacoides. Mar. Pollut. Bull. 64, 721-728. 
Cataldo, R.J., Hidalgo, L.M.E., Neaman, A., Gaete, O.H. 2011. Use of molecular biomarkers in Eisenia foetida to assess copper toxicity in agricultural soils affected by mining activities. J. Soil Sci. Plant Nutr. 11(3), 57-70.

Cuchiara, C.C., Silva, I.M.C., Martinazzo, E.G., Braga, E.J.B., Bacarin, M.A.; Peters, J.A. 2013. Chlorophyll Fluorescence transient analysis in Alternanthera tenella Colla plants grown in nutrient solution with different concentrations of copper. J. Agric. Sci. 5(8), 8-16.

Demmig-Adams, B. 1990. Carotenoids and photoprotection in plants. A role for the xanthophyll zeaxanthin. Biochim. Biophys. Acta. 1020, 1-24.

Genty, B., Briantais, J.M., Baker, N.R. 1989. The relationship between the quantum yield of photosynthetic electron transport and quenching of chlorophyll fluorescence. Biochim. Biophysica Acta. 990, 87-9.

Hoagland, D.R., Arnon, D. 1938. The water-culture method for growing plants without soil. Berkeley, California, University of California College of Agriculture, Agricultural Experimental Station. Circular. 347, 1-39.

Huang, W., Yang, S., Zhang, S., Zhang, J., Cao K. 2012. Cyclic electron flow plays an important role in photoprotection for the resurrection plant Paraboea rufescens under drought stress. Planta. 235(4), 819-828.

Kabata-Pendias, A., Pendias, H. 2001. Trace elements in soils and plants. CRC Press, Flórida. 315 p.

Mateos-Naranjo, E., Redondo-Gómez, S., Cambrollé, J., Figueroa, M.E. 2008. Growth and photosynthetic responses to copper stress of an invasive cordgrass, Spartina densiflora. Mar. Environ. Res. 66, 459-465.
Maxwell, K., Johnson G.N. 2000. Chlorophyll fluorescence: a practical guide. J. Exp. Bot. 51, 659-668.

Munekage, Y., Shinakai, T. 2005. Cyclic electron transport though photosystem I. Plant Biotechnol. 22, 361-69.

Low, J.W., Arimond, M., Osman, N., Cunguara, B., Zano, F., Tschirley D. 2007. A food-based approach introducing orange-fleshed sweet potatoes increased vitamin A intake and serum retinol concentrations in young children in rural Mozambique. J. Nutr. 137, 1320-1327.

Oukarroum, A., Madidi, S.E., Schansker, G., Strasser R.J. 2007. Probing the responses of barley cultivars (Hordeum vulgare L.) by chlorophyll a fluorescence OLKJIP under drought stress and re-watering. Environ. Experim. Bot. 60, 438-446.

Oukarroum, A., Perreault, F., Popovic R. 2012. Interactive effects of temperature and copper on photosystem II photochemistry in Chlorella vulgaris. J. Photochem. Photobiol. B Biol. 110, 9-14.

Perales-Vela, H.V., González-Moreno, S., MontesHorcasitas, C., Cañizares-Villanueva, R.O. 2007. Growth, photosynthetic and respiratory responses to sub-lethal copper concentrations in Scenedes musincrassatulus (Chlorophyceae). Chemosphere. 67, 2274-2281.

Redillas, M.C.F.R., Strasser, R.J., Jeong, J.S., Kim, Y.S., Kim, J.K. 2011. The use of JIP test to evaluate drought-tolerance of transgenic rice overexpressing OsNAC10. Plant Biotech. Report. 5, 169-175.

Rohácek, K., Barták, M. 1999. Technique of the modulated chlorophyll fluorescence: Basic concepts, useful parameters, and some applicatons. Photosynthetica. 37, 339-363. 
Shi-Sheng, K. 2007. Effects of copper on the photosynthesis and oxidative metabolism of Amaranthus tricolor seedlings. Agric. Sci. China. 6(10), 1182-1192.

Strasser, R.J., Srivastava A., Govindjee. 1995. Polyphasic chlorophyll a fluorescence transient in plants and cyanobacteria. Photochem. Photobiol. B 61, 32-42.

Strasser, R.J., Stirbet, A.D. 1998. Heterogeneity of Photosystem II probed by the numerically simulated chlorophyll a fluorescence rise (O-JI-P). Math. Comput. Simulat. 48, 3-9.

Strasser, A., Tsimilli-Michael, M., Srivastava, A. 2004. Analysis of the fluorescence transiente. In: Papageorgiou, G.C., Govindjee (eds). Chlorophyll Fluorescence: A Signature of Photosynthesis. Advances in Photosynthesis and Respiration Series, Springer, Dordrecht, pp: 321-362.

Strasser, R.J., Tsimilli-Michael, M., Qiang S., Goltsev, V. 2010. Simultaneous in vivo recording of prompt and delayed fluorescence and 820-nm reflection changes during drying and after rehydration of the resurrection plant Haberlea rhodopensis. Biochim. Biophys. Acta. 1797, 1313-1326.

Tsimilli-Michael, M., Strasser, R.J. 2008. In vivo assessment of plants' vitality: applications in detecting and evaluating the impact of Mycorrhization on host plants. In: Varma, A. (ed). Mycorrhiza: State of the Art, Genetics and Molecular Biology, Eco-Function, Biotechnology, Eco-Physiology, Structure and Systematics, Third Edition. Springer Verl., Dordrecht, pp: 679-703.
Violante, A., Cozzolino, V., Perelomov, L., Caporale, A.G., Pigna, M. 2010. Mobility and bioavailability of heavy metals and metalloids in soil environments. J. Soil Sci. Plant Nutr. 10(3), 268-292.

Yang, G., Yang, L., Jiang, Y.L., Li, Y., Wang, P., Chen, L. 2012. Physiological impacts of magnesiumdeficiency in citrus seedlings: photosynthesis, antioxidant system and carbohydrates. Trees. 26(4), 1237-1250.

Yusuf, M.A., Kumar, D., Rajwanshi, R., Strasser, R.J., Tsimilli-Michael, M., Govindjee, Sarin, N.B. 2010. Overexpression of $\gamma$-tocopherol methyltransferase gene in transgenic Brassica juncea plants alleviates abiotic stress: Physiological and chlorophyll $a$ fluorescence measurements. Biochim. Biophys. Acta. 1797, 1428-1438.

Xia, J., Tian, Q. 2009. Early stage toxicity of excess copper to photosystem II of Chlorella pyrenoidosa-OJIP chlorophyll a fluorescence analysis. J. Environ. Sci. 21, 1569-1574. 